\title{
DECOLONISING METHOD IN THE AGE OF \\ TRANSDISCIPLINARITY: A CASE FOR CONVERSATIONAL THINKING \\ DOI: https://dx.doi.org/10.4314/ajct.v1i1.3
}

\section{Submission: September 5, 2021 Acceptance: September 29, 2021 Isaiah Aduojo NEGEDU \\ Department of Philosophy \\ Federal University of Lafia \& \\ Fellow, School of Religion, Philosophy and Classics \\ University of KwaZulu Natal \\ ORCID: https://orcid.org/0000-0002-0444-1984}

\begin{abstract}
I will respond to two queries in this work. The first bothers on the possibility of having a single space in a transdisciplinary discourse. What will scholarship look like when we all come from our various vantage points? The second issue is a corollary of the first; will transcendence of disciplines be another ploy of coloniality to create a special breed that privileges one group over others? Overall, I argue that transdisciplinarity, as it stands, is inadequate since it silently promotes the exclusion of some methods. I will call for conversational thinking, which serves as a model for others to speak meaningfully and be heard.
\end{abstract}

Keywords: Decoloniality, method, conversational thinking, transdisciplinarity

\section{Introduction}

My interest in this theme is a product of the January 2020 decolonial summer school held at the University of KwaZulu Natal, South Africa. The issues I address here are fallouts of contributions among scholars, as well as my grievances. I am very much aware of the need for collaboration in scholarship. Thus, the coming together of disciplines is expected to create a more robust dialogue that should enrich society to the benefit of all and the detriment of none. 
Conversational philosophy is a growing philosophical way of thinking that emerges from a philosophical place, yet its application transcends the locale of its establishment. By the very method of conversational thinking, conversationalism reveals itself as reactionary, in that it struggles against the denial of a space in the dissemination of knowledge. With time, I have come to understand that the unavailability of space gradually transforms into the actual denial of possibilities for other systems of knowledge that are, for instance, 'non-western'. Conversational thinking thrives, despite the desire of absolutised hegemonism(s) to choke every rival ideology that begins to manifest itself as an alternative.

I, therefore, respond to problems that proceed from the need for transdisciplinary studies; the major problem, for me, being the suppression and subversion of 'rival' methods. Rivalry is actually the main setback of horizontal relationship. This is because all ideas in a horizontal relationship have the same goals, albeit different methods. The danger stems from the fact that there is always an attempt to foist a method from one context on another context, irrespective of its workability. Conversational thinking challenges dominant epistemologies in preference for multivalent alternatives.

This article will therefore be divided into three main parts: the first is an attempt to reconsider the goal of transdisciplinarity. The second will explicitly reflect on the idea of conversational thinking. In the third part, I will speak to the roadblocks to multivalent alternatives, and, with the use of conversational thinking, show how transdisciplinarity does not entirely fulfill its promise of the assurances of provincial knowledges. This will be backed by what we should do in order to get back on track.

\section{What is the Goal of Transdisciplinarity?}

Here I make a clear distinction between multidisciplinary, interdisciplinary and transdisciplinary perspectives before I state my grievance against transdisciplinary perspectives. Multidisciplinarity involves research conducted by researchers of various disciplines. Their results do not converge as research is done independently of each discipline. The ultimate goal is to provide solutions to 
problems, even if there appear to be several solutions to a particular problem. For the interdisciplinary perspective, different disciplines necessarily integrate their findings in order to come up with a more holistic solution to problems. Unlike the multidisciplinary paradigm where disciplines have the leverage to manage their successes thereby creating opportunities for several voices, the transdisciplinary approach seems to be more problematic within the context of decolonial methodologies. I say this because transdisciplinary studies make claim to the integration of ideas from different disciplines, while at the same time involving different stakeholders in the process of research (Gibbons 2013, 1286; HOFFMANN, POHL \& HERING 2017). The reason for this is the idea that any scientific research done should not be in isolation of praxis. This means that from the gathering of data to the implementation of results of research, both scholars and local communities/societies should be involved as partners. In terms of unification of disciplines for a more robust solution, transdisciplinarity has not shown to be a better alternative because of its inability to respond to some questions that would arise from its development.

Roland Scholz (2013) made a distinction between four types of transdisciplinarity: mode 1, basically, hinges on problem-solving without collaboration; mode 2 necessarily involves collaboration amongst scholars and stakeholders to provide practical solutions to concrete problems in the society; then we have the post-normal view (mode 3 ) that is animated by the claim that science has lost its credibility in the world, because of its involvement with nonscientific actors in a perverse manner. It is within this third definition that I situate the ploy of scientists who make themselves available as willing tools in the hands of research funding establishments so that through sponsorship from corporations, results are pre-determined. Beyond the post-normal is the fourth understanding of transdisciplinarity (mode 4), which is contained in the Charter of Transdisciplinarity ${ }^{1}$. This fourth understanding of transdisciplinarity

1 Basarab Nicolescu, "Charter of Transdisciplinarity" in Interdisciplinary Encyclopaedia of Religion and Science. 
states that science should have some moral character that enables it to acknowledge several solutions to problems and paths to knowledge. I use the example of the various covid-19 vaccines made by different companies but, at the same time, all geared towards resolving issues of global health. All these require the contributions of stakeholders in research outcomes since they will directly/indirectly be affected by the results. Sometimes, there is converging interest amongst all stakeholders and other times there is clash of interests. The main issue in a transdisciplinary discourse is how to harmonize detachments. The triple helix model can help to make harmony possible in research.

The triple helix model calls for a unification of the university, industry and government for effective collaboration (CARAYANNIS \& CAMPBELL 2013, 1295). This for me can also be problematic. This is because the various channels of involvement can usually be misused, with regards to the manipulation of results and implementation of outcomes. If there is going to be any promise in transdisciplinarity, the government should in the first place create an enabling environment for research activities to take place. As the first point of contact, public policies that affect education positively should be fixed. Without competent governmental institutions to drive policies, we cannot speak of collaboration with private sectors. The government should be an institution that performs dual roles in this triple helix model; the first being a lone institution that creates enabling policies for research in education. Without such policies, even the private sectors cannot collaborate with Universities since the ideas that should drive collaborations usually come from the colleges. After this level of policy actualisation has been fixed by government, it drives innovation in colleges and motivates private sectors to collaborate and provide grants for research.

As much as transdisciplinary research should have bearing on the immediate environment it hopes to impact, there are studies that need global implementation, which also means the application of rules universally. Will rules be made bearing in mind the

https://inters.org/Freitas-Morin-Nicolescu-Transdisciplinarity accessed 26/09/2021 
peculiarities of each community? An instance is the Covid-19 pandemic and the invention of vaccines. Research shows that there are racial/regional disparities in clinical trials, which in turn may likely harm disadvantaged groups (MODERNATX INC 2020, 5-54; PFIZER-BIONTECH 2020, 7,49). The common aim of the production of covid 19 vaccine should be to minimise, manage and if possible eliminate the pandemic globally. This means that if there is going to be vaccine trials based on population sampling, it should capture the aim of the project in mind. Let me turn to the Moderna and Pfizer vaccine trials. To what extent do those pharmaceutical companies take into consideration the overriding aim of the invention of the vaccine viz a viz the lack of inclusiveness of minorities when compared with dominant racial groups? To what extent does this example affects transdisciplinary research? There is no equality of opportunity during specific stages in the process. It is therefore most likely that there is bound to be fallouts and rightly so, from the production to the disbursement stages of the vaccine. When this scenario is transferred to other areas of endeavour, to what extent does transdisciplinarity acknowledge the existence of methods outside existing ones? "Transdisciplinarity, in particular, can only work satisfyingly if initiated from the very start; this means the construction of a common research aim and an institutionalized feedback pattern as part of the partner structure of the project during the setup phase" (SCHÖNENBERG, REGINE n.d.n. 2017, 184).

When you take the result of a research that has worked in a particular context and subject it to a different logicand a different context, there is bound to be problems. Addessing a particular problem from two different contexts, entail using different parameters, which also requires a review of methods. If and when different results are produced, based on the disparities in methods, there is going to be a clash of superiority of results. Scientific politics or power play comes into effect, and minority voices are bound to be suppressed in order that the world attempts a 'universal' application of knowledge gained. The problem arising from such universality is that such results are not a product of dialogue and, 
thus, only reinstalls the hegemony it purportedly claims to destroy. It is for this reason that Ulrike Felt, Judith Igelsböck, Andrea Schikowitz and Thomas Völker $(2013,512)$ are of the view that the validation of knowledge happens within localised contexts.

A fundamental problem that a researcher may encounter on her/his transdisciplinary journey is the question of managing surprises. Generally, researchers are comfortable with familiar methods and would indicate preference for such methods. The danger is to first ask the question: "does this make sense for the global north?" As a researcher, the primary purpose of any investigation is not to theorise but provide solutions and such solutions must apply to societies/communities. Only to the extent that knowledge is localised does it make meaning to a people. I think a scientist who comes into a community to solve a problem should be more engrossed with the locale of the research, not the nationality/indigeneity of the researcher. The latter becomes relevant if results from that locale are to be implemented in the permanent situs of the researcher. Under this condition, modification of results to suit different locales becomes relevant. This may also involve the use of novel methods that may not be part of conventional ones. In this sense, results of research may not be predetermined. Knowledge must therefore have contextual relevance (CLAUDIA 2014, 32).

We cannot also deny some manipulative practices in research, where multinationals and powerful individuals determine scientific results through the availability of funding to researchers who are willing to be bought to serve some hegemonic ends. This is not the same as patent for those whose invention need to be protected in order that they may enjoy reward for knowledge. ${ }^{2}$ Here, I make reference to pre-patent stage in research, where individuals/multinationals pay researchers huge sums of money in

\footnotetext{
${ }^{2}$ Here, I refer to research done by scholars whose main aim is to solve problems. The result from such research are patented so that those involved can get reward for hardwork and that no one steals their ideas. Profit-making is not the motivation for this category of scholars, but to proffer solutions, yet their solutions bring monetary reward to them.
} 
order to validate some projects/businesses that the individuals/multinationals do globally. Under the guise of grants for research, academics are given research projects and are also told at the pre-takeoff stage what the results of their research must be (Robin-Havt, 2016). Lee McIntyre (2018, 22-28) used the case of tobacco industry and oil companies sponsoring counter research to promote a narrative in favour of their businesses. Under such circumstances, the research is being compromised before it even begins. I make this claim because for every step in the research, the researchers ask themselves: "how does this stage support the predetermined result of the funder (even if to the detriment of the entire community)?

In order to allay the fears of scholars and create an open system that is free from ideological/cultural manipulations, conversationalism emerged as a viable alternative amongst others to allow people the opportunity to speak their truth. Although transdisciplinarity promises the emergence of provincial knowledge, this very goal of transdisciplinarity squares up with the conversational perspective. I will explain briefly this perspective of conversationalism in the next section.

\section{Conversationalism as a Progressive Method}

The creation of several solutions to a particular problem led to the contemplation of an included middle, which is against Aristotelian logic of excluded middle (BREDA 2007, 119). The logic of an included middle broadens our horizon and envisages a more open society that guarantees academic freedom unhindered by a few powerful individuals/corporations whose wealth become the determinant for credible research. Conversational thinking is a context-dependent system that exists to correct the deficit inherent in a bivalent system.

Here, I briefly explain what conversational philosophy is. At the same time, I give a background to the origins of conversational thinking. I must state at the onset that the idea/term/concept of 
"conversations" is not only attributable to the Conversational Society of Philosophy (CSP). For instance, Marcel Griaule wrote his masterpiece titled "Conversations with Ogotemmeli.", but this book exists as an informal conversation between two persons in the process of cultural unveiling, it does not bear the formal structure of conversational thinking that employs the trivalent system; the Socratic method bears some similarities to conversationalism and Richard Rorty also develped a conversationalist framework.

Literally, a conversation is an exchange of ideas, opinions, etc., between two or more people. There is, however. difference between the conversations as used in a somewhat informal sense, and by the above philosophers, and conversations as it used in a more proper sense by Jonathan Chimakonam and other members of the conversational school. In the Socratic dialogue emphasis is placed on telos, while in conversational thinking there is usually a progressive dialogue that does not focus on the end of a discourse. It opens the door to multivalent alternatives, hence creating possible futures that can be envisaged in scholarship, and it does this via a dynamic trivalent logic of inclusivity called Ezumezu logic. This logic is interesting in its adoption of the principle of included middle which allows scholars wade through complexities I ways that Aristoteliatype two valued logic cannot. Indeed, Nicolesu as cited by Breda $(2007,120)$ made reference to alternatives that go beyond a bivalent one thus: "The logic of the included middle is perhaps the privileged logic of complexity; privileged in the sense that it allows us to cross the different areas of knowledge in a coherent way."

Conversational philosophy is one of those rising methods that stands not in contrast to knowledge from the global north, but works on the similar task of attempting to understand reality from its perculiar context. It is for this reason I desist from using the term 'non-western' as a prefix to qualify knowledge production from the global south. Non-western may give the impression that there is a rivalry at play, with the possibility of a victor at the end. The mention of a trivalent logic as supplementary laws of thought explains a relationship, instead of an opposition to the Aristotelian bivalent-based logic. Some other systems known to me further 
explains the fact that logic from the global south did not discard bivalence. Rather, trivalence, logic of four alternatives and whatever may come afterwards all begin from the acknowledgement of bivalent alternative, while at the same time explaining its inadequacy for all regions of the world. Multivalent alternatives therefore is in a process of completing the universe, where everyone/region is both an actor and observer, teacher and student in a vast world.

As part of its guiding principle conversational thinking does not engage in such perverse discussions about the existence or nonexistence of African philosophy, but focuses on doing African philosophy. And so, we immediately see its progressive character as it focused on unveiling new ideas in African philosophy rather rehashing old problems and old ideas. This attitude of conversational thinking is what qualifies it to be a decolonial project.

This brings me to the brief core of conversationalism. Jonathan Chimakonam explains the rootedness of conversational thinking in the concept of iruka or arumaruka, which is used in two senses to mean either an act, or the medium through which the said act of critical engagement is employed. "In arumaristic relationships, there is only one position at a time and the party that holds and defends it is called nwa nsa" $(2017,17)$. There is a second party called $n w a$ nju that criticises the ideas of nwa nsa and compels $n w a$ $n s a$ to revise his/her ideas. Both nwa nsa and nwa nju complement each other. While the former needs the latter to revise its ideas so as to come up with more robust and viable ideas, the latter needs the former to fulfil its philosophic duty of 'devil's advocate', with the aim of encouraging $n w a$ nsa to provide reasons for beliefs. In the final analysis, conversational thinking projects the villagisation of knowledge since philosophic encounters should take into consideration the contexts that serve as both inspiration for the gathering of raw materials, and also the beneficiaries of knowledge. It is this project of localisation of knowledge and decentralization of same that should bring transdisciplinarity and conversational thinking into partnership. 


\section{Why Transdisciplinarity and Conversationalism should Converge}

Transdisciplinarity has one basic challenge; how to integrate different parties with different worldviews for collaboration. This very challenge is the main reason post-modernity came into force in the first place. It is clear from the charter of transdisciplinarity that diversity is not a problem. However, like other issues that border on identity, this very challenge calls for intentional swift action. I say this because there is the likelihood of inactivity that will span for many decades, while merely paying lip service to diversity. In the midst of integration, one pertinent unanswered question is: whose method(s) will researchers employ at the meeting point of transdisciplinarity? I pose this question not because it has not been answered in the charter, but because even a review of intended solutions for a different context or environment suggests that certain forms of diversity have been suppressed in favour of others. If some recipients would keep relying on a review of solutions to fit into their peculiar environment, then it would be difficult to speak of authenticity. This is where conversational thinking comes in. In promoting trivalence, conversational thinking gives room for multivalent alternatives. In acknowledging the peculiarities of every environment, it does recommend the localisation of knowledge, which necessarily implies familiarity with the methods in every environment.

Going by this understanding of conversational thinking, we see that it eschews any absolute universal order that compels humanity into a single frame of reference. It acknowledges the peculiarities of people, cultures, societies and so on. At the same time, conversational philosophy/thinking sees some benefits in the unity of human beings with various cultures. This is implicated in the fact that some of the canons of conversational philosophy give room for moderation where relevant ideas/practices from other cultures are tested based on their merits after undergoing revision in the recipient cultures (CHIMAKONAM 2015, 26-28). Thus, postmodernism does not deny the existence of some universal truths such as; all humans possess the faculty of reason. At the same time, 
conversational philosophy/thinking gives no room for oppressive forms of knowledge, which is mainly exemplified in the urge of hegemonic discourse to police other forms of knowledge with sole aim of determining what is being taught, what should be learnt and even who should be a teacher. Transdisciplinarity, to some extent, gives ample room for alternative forms of knowledge. Article 2 of the Charter of Transdisciplinarity states that: "The recognition of the existence of different levels of reality governed by different types of logic is inherent in the transdisciplinary attitude. Any attempt to reduce reality to a single level governed by a single form of logic does not lie within the scope of transdisciplinarity."

In practice, however, researchers engaged in transdisciplinary studies do not take into account the charter of transdisciplinarity. At best, there is a reliance on a single method in the search for solutions to problems. It is this divergence between ideas and praxis that betrays transdisciplinarity and makes it argue with itself. Let me briefly explain what I mean here. Transdisciplinarity is so-called because it involves all parties in the quest for progress. It also means that engagement in transdisciplinary research implies the localisation of knowledge because, in the Deweyan perspective, ideas must work in praxis within a particular context if it must be credible. If there is a switch in logic from one society to another without revision that takes into account the peculiarities of the recipient community, then $\mathrm{ab}$ initio there is already a deviation from the transdisciplinary perspective, because what makes it transdisciplinary is its responsiveness to article two of the charter of transdisciplinarity. Any knowledge production that does not impact a people positively is epistemicidal. It is in this context of improving a community, or a people that we should frown at research that is done strictly for profit. In the final analysis, knowledge is not meant for capital profit, but to add value. It is the creation of value that should engineer

3 Basarab Nicolescu, "Charter of Transdisciplinarity", in Encyclopaedia of Religion and Science. https://inters.org/FreitasMorin-Nicolescu-Transdisciplinarity accessed 26/09/2021. 
profit. That an individual engages in a research does not also mean that value is being added. Profit making is not the same as value creation. The distinction between these two goes to the ethics of research. A research can begin with an altruistic goal in the mind of the researchers. At the same time, industries and governments as the case may be, could then take over the results of such findings to the extent of the alignments of their various interests. At this stage, profit and not value becomes the first marker for successful research. The existence of co-created knowledge for public interest is possible, and provides a picture of how society should function. But the triple helix relationship is presented as an ideal. It does not give honest criteria of how the world of research truly works. In a triple helix model of transdisciplinary relationship, there is always the policymaker (government), funder (industry), and the researcher (university). Because of the dependence of the researcher on the funder, research results sometimes must align with the donor's interest, even if the interest is not the public's interest. The donor is usually into business and as a capitalist investor, the primary aim is to get profit for his/her investments. It is also not unlikely for some policymakers to have a stake in the funding. This implies that it is easiest to find alignments among the policymaker and funder over the researchers.

In the final analysis, the biggest investor gets the biggest profit. This is a more refined way of censorship that was symptomatic of preindustrial Europe. In that era, religious authorities solely and directly determined what should be acceptable as research 'truths'. If a particular scientific finding was contrary to the 'redemptive will' of religious organisations, the scientist was either asked to align his findings with that of the institution, or discard. Religious figures went as far as censoring ideas in the guise of public interest in order to maintain perpetual dominance in the world. This was not a fight for truth, but a war of superiority of truth that is solely determined by power play (ANDERSSON \& ANDERSSON 2020, 237). Where is the community in all of this? In manufacturing and supply of goods, the community is the consumer and also serves as victim-recipient. As passive observers who are part of 
transdisciplinary process, their usefulness is to the extent that they are consumers of goods without input on how the end products affect them adversely. In conversational thinking, the community is made up of persons, not instrumentalised tools whose value can only be viewed in terms of monetary capital.

In an attempt to defend the knowledge-based economy as a core element in the triple helix relationship, Hughes expressed optimism in a service-dominant logic (SDL) over a goods-dominant logic (GDL). In SDL, the focus shifts from the producer to the consumer. The movement of this logic is questionable within the context of government-industry-academia relationship. Hughes (2014, 339) claims that: "as authority moves away from producer to consumer, a command and control approach will no longer work." The problem with this logic is the fact that the supplier in the triple helix chain is mistaken for the industry. The industry is the tangible supplier (operand), while the researcher is the intangible supplier (operant). The latter necessarily comes before the former in a relationship. It is the latter that supplies to the former. In that case, the researcher can choose to cut off supply to the industry, but it is a rare condition since the researcher needs reward for hard work. At the point of contact between the industry and the public the game changes to a service-dominant system. It is my view that we can still have SDL that ceases to emphasise dominance and places emphasis on delivery. What is needed is a service-dominant logic (SDL) that is transformed into service-delivery logic (SDL). In that case, there should be an intentional movement from a vertical to a horizontal chain of relationship. This is what real co-creation should entail; that gives voice to the public to determine their futures through ethical review of all processes. This is the primary function of an uncompromising policy maker (government). Businesses with public value are very much interested in any environment that provides a safe ground for investment. However, the government should put the right policies in place to encourage investors. 


\section{Conclusion}

I have briefly explained transdisciplinarity and the basic principle of conversational thinking. I have also explained where transdisciplinarity and conversational thinking can meet in order to produce a more sincere scholarship. The very clear difference for me between transdisciplinarity and conversational thinking is that while the former claims to do all that the latter promises to do, conversational thinking does not just promise, but actually engages its task in praxis. Transdisciplinarity therefore appears to be an idea that needs conversational thinking to work in reality. When scholars meet at the transdisciplinary level, there is need for more openness in order to have results that dovetail to community. Regionalisation of outcomes also means revision of methods to accommodate other competent worldviews and give people freedom to own and take responsibility for their futures. Conversational thinking brings that liberal outlook to scholarship in a more critical way that makes it possible to sieve authentic scholarship from perverse ones.

\section{Relevant Literature}

1. ANDERSSON, David \& ANDERSSON, Ake. "The Impossibility of the Triple Helix," [Prometheus], pp235-252, 2020. Vol 36. No3.

2. BREDA, John. "Towards a Transdisciplinary Hermeneutics: A New Way of Going Beyond the Science/Religion Debate," [Transdisciplinarity in Science and Religion, Magdalena STAVINSCHI. Ed.], pp103-156, 2007. Curtea Veche Publishing House: Bucharest.

3. BINDER, Claudia. "Transdisciplinarity: Co-creation of Knowledge for the Future," [RCC Perspective], pp31-34, 2014. Vol 2.

4. CARAYANNIS, Elias \& CAMPBELL, David. "Mode 3 Knowledge Production in Quadruple Helix Innovation Systems: Quintuple Helix and Social Ecology," [Encyclopedia of Creativity, Invention, Innovation, and 
Entrepreneurship, Elias G. CARAYANNIS Ed.], pp12931299, 2013. Springer: New York.

5. "Charter of Transdisciplinarity," Adopted at the First World Congress of Trandisciplinarity, Convento da Arrábida, Portugal, November 2-6, 1994.

6. CHIMAKONAM, Jonathan. "Conversational Philosophy as a New School of Thought in African Philosophy: A Conversation with Bruce Janz on the Concept of Philosophical Space," [Confluence Online Journal of World Philosophies], pp9-40, 2015. Vol 3.

7. CHIMAKONAM, Jonathan. "Conversationalism as an Emerging Method of Thinking in and Beyond African Philosophy," [Acta Academica], pp11-33, 2017. Vol 49. No2.

8. MCINTYRE, Lee. [Post-Truth], 2018. The MIT Press: Massachusetts.

9. MODERNATX, INC. "FDA Briefing Document: Moderna COVID-19 Vaccine," pp5-54, December, 2020. June, 2021. Web

10. FELT, U. IGELSBOCK, J. SCHIKOWITZ, A. VOLKER, T. "Growing into what? The (un-)disciplined Socialisation of Early-stage Researchers in Transdisciplinary Research," [Higher Education], pp511-524, 2013. Vol 65. No4.

11. GIBBONS, Michael. "Mode 1, Mode 2, and Innovation," [Encyclopedia of Creativity, Invention, Innovation, and Entrepreneurship, Elias G. CARAYANNIS Ed.], pp12851292, 2013. Springer: New York.

12. HOFFMAN, Sabine., POHL, Christian., \& HERING, Janet. "Methods and Procedures of Transdisciplinary Knowledge Integration: Empirical Insights from Four Thematic Synthesis Processes," [Ecology and Society], 2017. Vol 22. No 1.

13. HUGHES, T. "Co-creation: Moving Towards a Framework for Creating Innovation in the Triple Helix," [Prometheus], pp337-350, 2014. Vol 32. No 4. 
14. PFIZER-BIONTECH. "FDA Briefing Document: PfizerBioNTech COVID-19 Vaccine," pp7-49, December, 2020. June, 2021.

15. RABIN-HAVT, Ari. [Lies, Incorporated], 2016. Anchor Books: New York.

16. SCHOLZ, Roland. "Transdisciplinarity: Theory and Visions on Global Transdisciplinary Processes for Adapting to Climate Change," [Climate Change: International Law and Global Governance, Oliver RUPPEL, Christian ROSCHMANN \& Katharina RUPPEL-SCHLICHTING Eds], pp329-355, 2013. Nomos Verlagsgesellschaft $\mathrm{mbH}$ : Baden-Baden.

17. SCHÖNENBERG, Regine., n.d.n.. "Experiences of Interand Transdisciplinary Research: A Trajectory of Knowledge Integration Within a Large Research Consortium," [Erdkunde], pp177-193, 2017. Vol 71. No 3. 